\title{
Opening note
}

Most of my public life has been committed to confronting poverty and inequalities, the discriminations from which they arise and the deprivations they bring about.

Inequalities undermine universal rights, social progress and economic and political stability. For those living in poverty, basic rights are often out of reach.

It is clear to me that reducing inequalities and ending poverty is the path to achieving universal human rights for all.

The COVID-19 pandemic has exposed systemic failures to uphold human rights. Its uneven incidence and impact unmasked deep, diverse and pervasive inequalities in every society in every corner of the globe. Sadly, but not surprisingly, the most vulnerable to the pandemic have been those already at risk, including people living in poverty.

Now we are assessing not whether, but how much, the pandemic will set back our efforts to achieve the Sustainable Development Goals by 2030. We are faced with the prospect that the pandemic will drive tens of millions of people into extreme poverty, undoing a decade or more of development gains. It's a stark and striking example of how depriving people of their social and economic rights kills and of the real need to prioritize economic, social and cultural rights of all those in a precarious state.

The safety and prosperity of all is dependent on how we address the needs of everyone, including the less fortunate. Leaving no one behind is not only a moral imperative, it is a practical one. We cannot afford to leave millions without access to water, without adequate housing or in poverty. It is simply not acceptable to move back to the way things were. It is our duty to build back better.

That means adopting strong, transformative measures to heighten the powerful protections that human rights-based policies can provide - by promoting public health, trust and greater social and economic resilience.

It means forging a new economy that is environmentally sustainable and equitable, fair and inclusive.

It means leadership grounded in clarity, evidence and principle to protect the most vulnerable members of society. And it means the full respect of all rights, political, economic, civil, social and cultural.

In sum, building back better requires the unequivocal recognition that poverty is a violation of human dignity and an assault of fundamental human rights.

This is an issue of urgent concern to my Office and myself. By providing a human rights perspective to diverse and intersecting challenges related to poverty, this book and its authors bring an inestimable contribution to the discussion.

Michelle Bachelet, United Nations High Commissioner for Human Rights 